\title{
Soil compressibility as measured in the oedometer
}

STAMATOPOUlOS, A. C. \& KOTZIAS, P. C. (1978). Géotechnique 28, No. 4, 363-375

\section{K. Senneset and L. I. Finborud, The Norwegian Institute of Technology}

The Authors apply arithmetic plots of the stress-strain curves, and a 'constrained modulus' which they denote as $D$ (in reality a tangent modulus). They also observe that $D$ depends on effective stress. The observed dependency is formalized by ' $U$ shaped' curves. The reader may be led to believe that this shape is applicable to most types of soil, therefore a few comments on these findings may be appropriate.

First of all, the introduction of arithmetic stress-strain plots, and the tangent modulus concept

$$
M=\frac{\mathrm{d} \sigma^{\prime}}{\mathrm{d} \varepsilon}
$$

has been used consistently for most types of soils at our University for almost 20 years, see Janbu $(1963,1967)$. Our experience is that a ' $U$ shape' is much too restrictive for covering
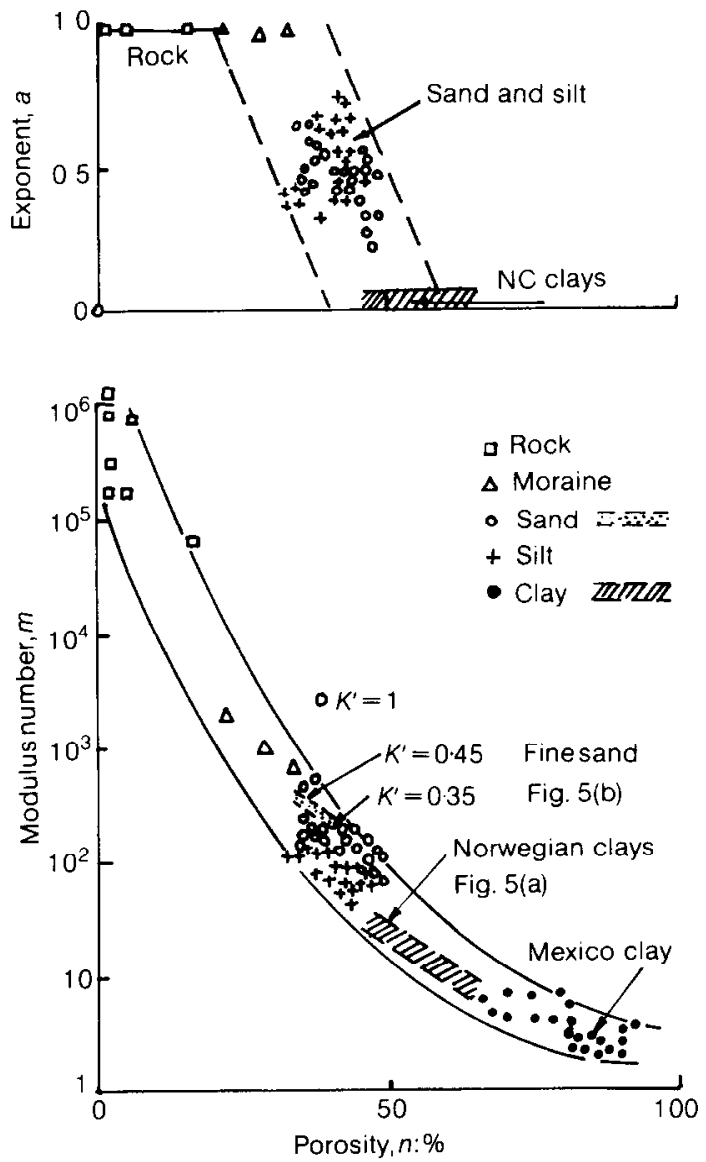

Fig. 1. Variation of stress exponent $a$ and modulus number $m$ with porosity 
several types of soils. We have found Janbu's formulation is more diversive. It reads

$$
M=m \sigma_{a}\left|\frac{\sigma^{\prime}}{\sigma_{a}}\right|^{1-a}
$$

where $m=$ modulus number

$\sigma_{\mathrm{a}}=1$ atmosphere $\sim 1 \mathrm{~kg} / \mathrm{cm}^{2}$

$a=$ pure number between 0 and 1 .
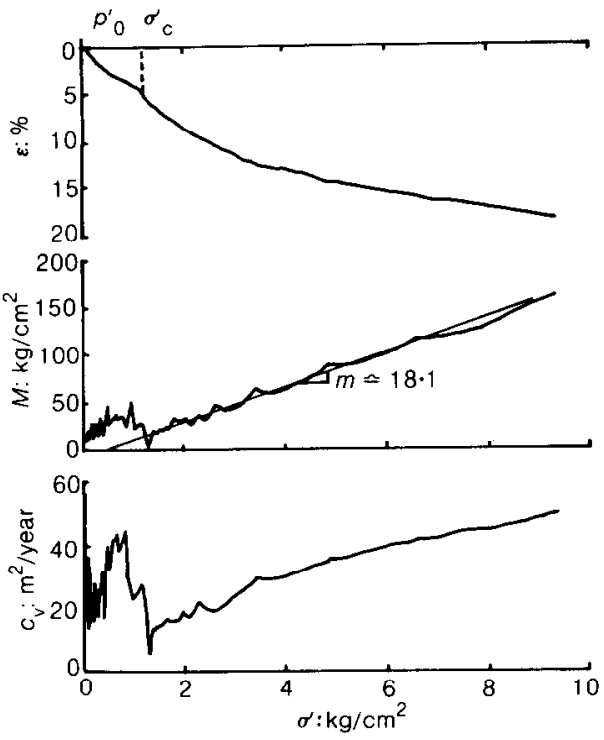

Fig. 2. Continuous consolidation

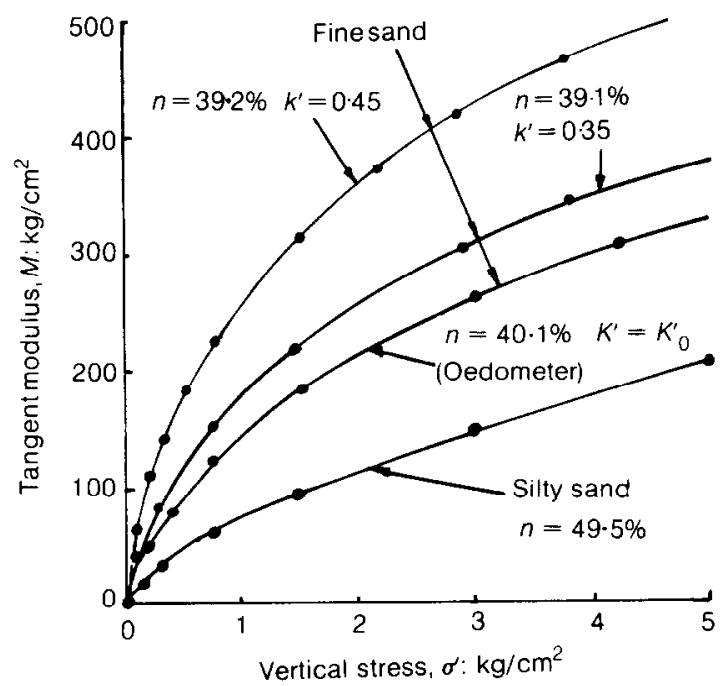

Fig. 3. Compressibility tests on sand 

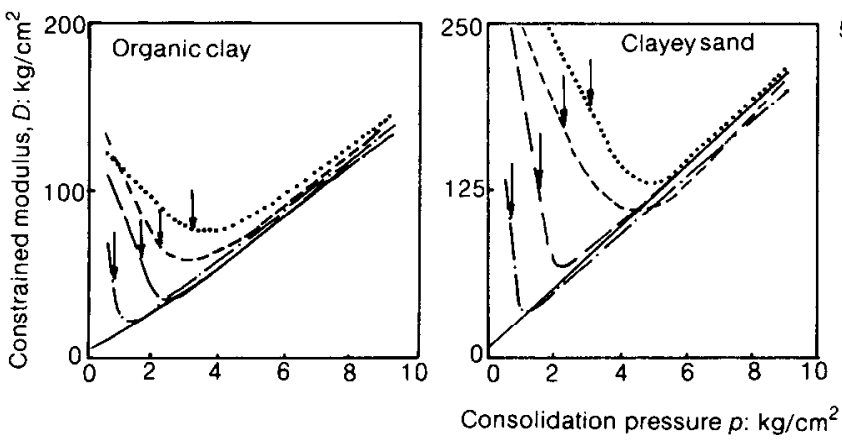

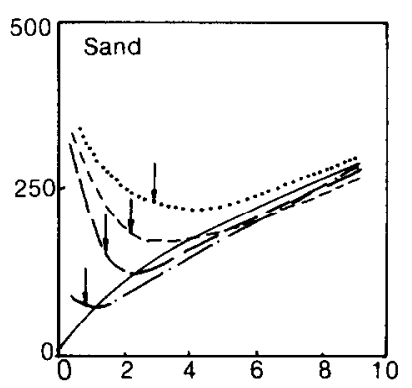

Key

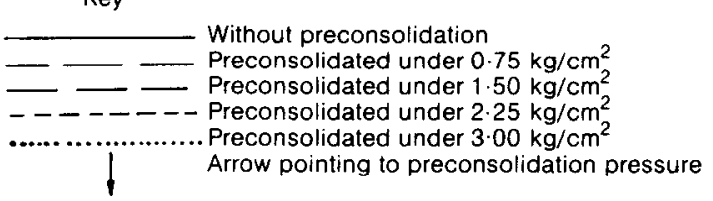

Fig. 4. Effect of preconsolidation on the shape of the $D$ against $p$ plot for three different soils

Typical variations of the parameters $a$ and $m$ for many types of soils of variable porosity are shown in Fig. 1. The preconsolidation pressure $\sigma_{\mathrm{c}}{ }^{\prime}$ is a very important value to determine from compressibility test. The conclusion from our research so far is that the combined use of the $\varepsilon-\sigma^{\prime}, M-\sigma^{\prime}$ and $c_{\mathrm{y}}-\sigma^{\prime}$ curves will give the best basis for the evaluation of $\sigma_{\mathrm{c}}{ }^{\prime}$.

An example is shown in Fig. 2, which shows results obtained by a new oedometer technique. It differs from the CRS test (constant rate of strain) in that its rate of deformation is guided by the value $\dot{u} / \dot{p}$ which is kept constant during the test.

For illustration purposes, some results from tests on sand and silty sand are shown in Fig. 3. This figure demonstrates that the ' $U$ shape' is lost.

\section{REFERENCES}

Janbu, N. (1963). Soil compressibility as determined by oedometer and triaxial tests. Proc. Eur. Conf. I, Wiesbaden. (See also discussions, V, Vol. II.)

Janbu, N. (1967). Settlement calculations based on the tangent modulus concept. Three guest lectures at Moscow State University. Bulletin No. 2 of Soil Mechanics and Foundation Engineering at the Technical University of Norway, Trondheim.

Janbu, N. (1969). The resistance concept applied to deformations of soils. Proc. 7th Int. Conf. Soil Mech. Fdn Engng, Mexico 1, 191-196, Mexico. (See also discussions.)

\section{Authors' reply}

The term constrained modulus and its notation by the letter $D$ are not being used for the first time in our Paper (see for example, Lambe and Whitman, 1969).

The $U$ shape of the $D$ against $p$ plot is, in our experience, applicable to most types of soils. It is, therefore, desirable to reconsider exponential expressions like equation (2) of the discussion, because such expressions fail to describe adequately the relationship between compressibility and consolidation pressure in the most significant range of low values of pressure. For example, the variation of $M$ with $\sigma^{\prime}$ in Fig. 2 of the discussion cannot be approximated by an exponential expression in the range of values of $\sigma^{\prime}$ between zero and $1.5 \mathrm{~kg} / \mathrm{cm}^{2}$; the results for values of $\sigma^{\prime}$ greater than $0.5 \mathrm{~kg} / \mathrm{cm}^{2}$ can, however, be fitted by a $U$ shaped curve; between the values of $\sigma^{\prime}$ of zero and $0.5 \mathrm{~kg} / \mathrm{cm}^{2}$ the experimental results do not conform either to the 
$U$ shape or to the exponential configuration, but this is a range of pressures for which seating and other experimental errors are likely to be particularly important.

Exponential expressions like equation (2) of the discussion are most nearly applicable to soils that have small or no preconsolidation. With increasing preconsolidation the $U$ shape of the $D$ against $p$ or equivalent plots becomes more and more pronounced. The effect of preconsolidation on the shape of the plot is illustrated in the accompanying Fig. 4 for three different types of soil, i.e. (a) a remoulded organic clay with liquid limit of $82 \%$, plasticity index of $27 \%$, silt and clay sizes of $86 \%$, specific gravity of 2.83 and initial water content of $56 \%$; (b) a remoulded clayey sand with liquid limit of $31 \%$, plasticity index of $14 \%$, silt and clay sizes of $43 \%$, specific gravity of 2.75 and initial water content of $28 \%$; and (c) loose nonplastic sand with silt sizes of $5 \%, 48 \%$ passing through sieve No. $50,99 \%$ passing through sieve No. 10 , specific gravity of 2.64 , subangular, initial dry density of $1 \cdot 10 \mathrm{~g} / \mathrm{cm}^{3}$. From each of the three soil samples used, a series of five, as nearly identical as possible, oedometer specimens were prepared in a very loose condition; one of the specimens in each series was tested without preconsolidation but the remaining four were tested after first loading to $0.75 \mathrm{~kg} / \mathrm{cm}^{2}, 1.50 \mathrm{~kg} / \mathrm{cm}^{2}, 2.25 \mathrm{~kg} / \mathrm{cm}^{2}$ and $3.00 \mathrm{~kg} / \mathrm{cm}^{2}$ and then unloading (Fig. 4).

As exponential expressions (such as equation (2) of the discussion) are applicable to soils that have a small or no preconsolidation, they could be regarded as a particular form of the more general case of the $U$ shape curve, with the left half of the $U$ reduced to trivial size.

\section{REFERENCE}

Lambe, T. W. \& Whitman, R. V. (1969). Soil Mechanics. New York: John Wiley and Sons.

\section{A Note on Hvorslev's intake factors}

LOWTHER, G. (1978). Géotechnique 28, No. 4, 465-466

\section{E. G. Youngs, Physics Department, Rothamsted Experimental Station}

The Author draws attention to a difficulty encountered in the evaluation of permeability values from data obtained from tests on boreholes and piezometers. He notes that the formulae given by Hvorslev $(1949,1951)$ for the cases of a well point-filter are, in the limit of zero length of filter, different from those given for a flush bottom well, although they should be identical. This is not so surprising, since Hvorslev himself points out the approximate nature of some of the formulae he uses. This discussion outlines the physical basis of their derivation, and gives a comprehensive table of values of the shape factor which allows the determination of permeability from borehole tests for different lengths of filter and depth of well.

In the derivation of the intake formulae, which have the general form

$$
q=S k H D
$$

where $q$ is the discharge, $k$ the permeability of the soil, $H$ the head causing the flow, $D$ the diameter of the well point-filter, and $S$ a shape factor the value of which depends on the shape of the cavity and its depth relative to the impervious boundary, Hvorslev (1951) notes that sometimes assumptions concerning the shape of the well point-filter (or cavity below the end of the well) were made.

This was the case for the formulae obtained by Dachler (1936), quoted by Hvorslev, for the well point-filter or hole extended both in an infinite uniform soil and at an impervious 